\title{
A novel serovar of Shigella dysenteriae from patients with diarrhoea in Bangladesh
}

\author{
Kaisar A. Talukder, ${ }^{1}$ Abdus S. Mondol, ${ }^{1}$ M. Aminul Islam, ${ }^{1}$ Zhahirul Islam, ${ }^{1}$ \\ Dilip K. Dutta, ${ }^{1}$ Bijay K. Khajanchi, ${ }^{1}$ Ishrat J. Azmi, ${ }^{1}$ M. A. Hossain, ${ }^{1}$ \\ M. Rahman, ${ }^{2}$ Thomas Cheasty, ${ }^{3}$ Alejandro Cravioto, ${ }^{1}$ G. B. Nair ${ }^{1}$ \\ and David A. Sack ${ }^{1}$
${ }^{1}$ ICDDR,B: Centre for Health and Population Research, GPO Box 128, Dhaka 1000, Bangladesh ${ }^{2}$ Department of Biochemistry and Molecular Biology, University of Dhaka, Dhaka 1000, Bangladesh
${ }^{3}$ Laboratory of Enteric Pathogens, Health Protection Agency, Centre for Infections, Colindale, London NW9, UK

\begin{abstract}
Every year, around $3 \%$ of isolates from patients with diarrhoea at Dhaka Hospital, ICDDR,B, are identified as Shigella-like organisms (SLOs) based on their activity in biochemical tests. These isolates do not react with any of the current Shigella antisera including all existing and provisional serotypes. Among these SLOs, a unique cluster of seven isolates with an identical plasmid profile was found and these isolates were further characterized by phenotypic and genotypic techniques. All were nonlactose fermenters, with an identical biochemical pattern typical of Shigella dysenteriae. They were classified as invasive since they harboured the $140 \mathrm{MDa}$ invasive plasmid, were able to bind Congo red, produced keratoconjunctivitis in the guinea pig eye, and were positive by PCR for the ipaH gene and Shigella enterotoxin 2 [ShET-2] gene. All isolates were resistant to ampicillin, tetracycline and sulfamethoxazole-trimethoprim but were susceptible to mecillinam, nalidixic acid, ceftriaxone and ciprofloxacin. Six of the isolates were identical in DNA pattern by PFGE with the seventh exhibiting a closely related pattern; both patterns were distinguishable from all other Shigella and Escherichia coli patterns. An antiserum prepared against one of the isolates reacted with all isolates and did not cross-react with other Shigella and $E$. coli serotype reference strains. It is therefore proposed that these isolates represent a new provisional serovar of S. dysenteriae, type strain KIVI 162.
\end{abstract}

Received 12 October 2006 Accepted 8 January 2007

\section{INTRODUCTION}

Shigellosis is one of the major diarrhoeal diseases in Bangladesh and other developing countries. It has been estimated that more than 95000 children $<5$ years of age die of shigellosis annually in Bangladesh (Kotloff et al., 1999). Shigella is spread by direct faecal-hand-oral contact wherever personal hygiene is compromised (Weissman et al., 1975) and outbreaks are difficult to control because of the low infectious dose of the organisms (DuPont et al., 1989).

The genus Shigella comprises four subgroups that historically have been considered species (Enterobacteriaceae Subcommittee of the Nomenclature Committee of the International Association of Microbiological Societies, 1958): subgroup A is referred to as Shigella dysenteriae, subgroup B as Shigella flexneri, subgroup C as Shigella boydii and subgroup D as Shigella sonnei. Speciation of Shigella is not easily achieved based on biochemical

Abbreviation: SLOs, Shigella-like organisms. properties alone, and definitive identification requires serotyping to be performed (Ewing et al., 1958; Ewing \& Lindberg, 1984). Based on somatic O antigens, S. dysenteriae is subdivided into 15 serogroups (Bopp et al., 2003) and 2 provisional serogroups (Coimbra et al., 2001; Melito et al., 2005) and S. flexneri into 6 serogroups with 14 subserotypes (Bopp et al., 2003). S. boydii comprises 19 serogroups. Ewing (1986) acknowledged 17 serogroups, which included two provisional serogroups represented by reference strain $2710-54$ as $S$. boydii 16 and $3615-53$ as $S$. boydii 17. Gross et al. (1980) reported a new provisional serogroup isolated in Bangladesh and designated serogroup 18 with the reference strain E10163. Recently, provisional S. boydii serovar E16553, designated serogroup 19, has been reported by several groups from diverse geographical origins (Gross et al., 1982; Ansaruzzaman et al., 2005); and serogroup 20 was recently proposed and confirmed as novel by Woodward et al. (2005).

In a previous study, we found that a significant number of strains isolated between 1999 and 2002 had biochemical properties typical of Shigella but could not be serotyped 
following the current serotyping scheme (Talukder et al., 2003). These strains were designated Shigella-like organisms (SLOs) and approximately $3 \%$ of Shigella infections at ICDDR,B hospital are caused by the such organisms (Talukder et al., 2003). The prevalence of SLOs has increased over the years, accentuating the necessity for extensive characterization of these strains. In a retrospective study, we tested all SLOs with all available antisera specific for Shigella including existing, provisional and atypical types. Isolates were also tested for plasmid profiles as most Shigella serotypes contain a wide array of plasmids, some of which are serotype specific (Talukder et al., 2003). This revealed a cluster of seven isolates with identical plasmid patterns and which were not agglutinated by Shigella antisera. We describe here the properties of these isolates with respect to activity in biochemical tests, the presence of pathogenicity-associated genes, chromosomal DNA profiles and reactivity with a serum raised against one of their number.

\section{METHODS}

Isolates. Seven isolates from 153 SLOs isolated from patients with diarrhoea attending the Dhaka Treatment Centre operated by ICDDR,B in Bangladesh were selected for this study. These isolates were non-reactive with available Shigella antisera and were isolated in the clinical microbiology laboratory with standard biochemical and microbiological methods (World Health Organization, 1987). All isolates were tested further in API 20E kits (bioMérieux). Strain E112707-96, provisional S. dysenteriae serotype, was received from $\mathrm{Dr}$ Thomas Cheasty, ESYV Reference Laboratory (Laboratory of Enteric Pathogens, Health Protection Agency, Centre for Infections, London, UK). YSH6000, S. flexneri 2a (Talukder et al., 2002), and an Escherichia coli strain (ATCC 25922) lacking the $140 \mathrm{MDa}$ invasive plasmid and susceptible to all antibiotics were used as positive and negative controls, respectively, in the Sereny test, Congo red binding ability test, and in the PCR assay for detection of ipaH and Shigella enterotoxin genes $($ set $)$.

Biochemical characterization. Isolates were subjected to a range of biochemical tests by conventional methods as described by Ewing (1986).

Serotyping. Isolates were tested in the local laboratory with commercially available antisera (Denka Seiken) specific for all recognized Shigella serovars and with antisera raised against serovars S. dysenteriae 13, 14 and 15. They were subcultured on MacConkey agar (Difco, Becton Dickinson) and incubated for $18-20 \mathrm{~h}$ at $37{ }^{\circ} \mathrm{C}$. Slide agglutination tests were performed as described previously (Talukder et al., 2002). Isolates were also tested in the ESYV reference laboratory with all available serogroups of Shigella and E. coli. An antiserum was raised in rabbits against a heat-killed suspension of a representative isolate (KIVI 162) according to the protocol of Ewing \& Lindberg (1984). This antiserum was tested against other SLOs, S. dysenteriae serotypes 13, 14 and 15, S. boydii serotypes 19 and 20, and enteroinvasive E. coli serotypes O28ac, O29, O124, O136, O143, O144 and $\mathrm{O} 164$.

Agglutinin-absorption tests. When cross-reactions were found, reciprocal absorptions were performed to determine the extent of the antigenic relationship between the strains (Wathen-Grady et al., 1985). Serological cross-reactions were considered significant if the heterologous titre was $\geqslant 1 / 16$ of the homologous titre.
Antimicrobial susceptibility. Susceptibility to antimicrobial agents was determined on Mueller-Hinton agar by the disc diffusion method following the guidelines of the Clinical and Laboratory Standards Institute (2004). The antimicrobial discs used were ampicillin $(10 \mu \mathrm{g})$, tetracycline $(30 \mu \mathrm{g})$, mecillinam $(25 \mu \mathrm{g})$, nalidixic acid $(30 \mu \mathrm{g})$, sulfamethoxazole-trimethoprim $(25 \mu \mathrm{g})$, ciprofloxacin $(5 \mu \mathrm{g})$ and ceftriaxone $(30 \mu \mathrm{g})$. E. coli ATCC 25922 and Staphylococcus aureus ATCC 25923 were used as control strains.

Keratoconjunctivitis assay. This test was performed according to the procedure of Sereny (1957). Briefly, an overnight culture of bacteria, of approximately $10^{10}$ viable cells in $20 \mu \mathrm{l}$ PBS, was introduced into the conjunctival sac of the guinea pig. The other eye served as the control. The guinea pigs were observed daily for $72 \mathrm{~h}$ and inflammatory responses were graded. The experimental procedures were approved by the animal experimentation ethics committee of the ICDDR,B.

Congo red binding ability. Trypticase soy broth containing $0.3 \%$ yeast extract with $1.5 \%$ agar supplemented with $0.01 \%$ Congo red (Sigma) was used to study the pigment binding ability of isolates according to the procedures of Sasakawa et al. (1986).

Detection of virulence genes by PCR. DNA was prepared from the seven isolates and examined by PCR for the presence of the invasionassociated locus ( $\mathrm{ial}$ ) and the invasion plasmid antigen $\mathrm{H}(\mathrm{ipaH})$ of Shigella (Vargas et al., 1999). PCR to demonstrate the presence of Shiga toxin $1\left(s t x_{1}\right)$ and Shigella enterotoxins (set1 and sen) was performed according to published procedures (Bonnet et al., 1998; Vargas et al., 1999). Primer sequences are listed in Table 1; reactions were performed in a thermal cycler (PTC-200; MJ Research) and amplification products were separated by $1 \%$ agarose gel electrophoresis and stained with ethidium bromide.

Plasmid DNA. Plasmid DNA was prepared according to the alkaline lysis method of Kado \& Liu (1981) with some modifications (Talukder et al., 2002). The molecular mass of the plasmid DNA bands was assessed by comparison with the mobility of known molecular mass plasmids in E. coli PDK-9, $\mathrm{R}_{1}, \mathrm{RP}_{4}, \mathrm{Sa}$ and V517 in agarose gels (Talukder et al., 2002).

PFGE. Intact agarose-embedded chromosomal DNA was prepared, digested with $\mathrm{XbaI}$ (Gibco-BRL), and restriction fragments were resolved in a contour-clamped homogeneous electric field (CHEFDRII) apparatus (Bio-Rad) following the procedure of Talukder et al. (2002). Pulse times were 1-6 s for $9 \mathrm{~h}, 3-40 \mathrm{~s}$ for $12 \mathrm{~h}$, and 5-70 s for $13 \mathrm{~h}$. The gel was stained, destained and photographed on a gel documentation system and bands were sized against a 48.5-1000 kb molecular mass ladder (Bio-Rad).

\section{RESULTS}

\section{Biochemical characterization}

All isolates showed biochemical reactions typical of Shigella species. They were oxidase- and catalase-negative, and did not ferment D-mannitol, sucrose, lactose, rhamnose, raffinose, xylose, trehalose or dulcitol. All utilized arginine and were lysine- and ornithine-negative. API 20E tests identified all isolates as Shigella species.

\section{Serotyping}

All isolates were negative in agglutination tests for Shigella and E. coli serotypes and reacted only with the antiserum 
Table 1. Primers and conditions used for identification of virulence genes of Shigella spp.

\begin{tabular}{|c|c|c|c|c|c|}
\hline $\begin{array}{l}\text { Gene encoding } \\
\text { virulence factor }\end{array}$ & Primer & $\begin{array}{l}\text { Oligonucleotide } \\
\text { sequence }\left(5^{\prime}-3^{\prime}\right)\end{array}$ & $\begin{array}{c}\text { Location } \\
\text { within gene }\end{array}$ & $\begin{array}{c}\text { Size of the amplified } \\
\text { product (bp) }\end{array}$ & Reference \\
\hline \multirow[t]{2}{*}{$i p a H$} & Shig-1 & TGGAAAAACTCAGTGCCTCT & $1063-1083$ & 423 & Vargas et al. (1999) \\
\hline & Shig-2 & CCAGTCCGTAAATTCATTCT & $1466-1485$ & & \\
\hline \multirow[t]{2}{*}{ ial } & ial upper & CTGGATGGTATGGTGAGG & $5340-5357$ & 320 & Vargas et al. (1999) \\
\hline & ial lower & GGAGGCCAACAATTATTTCC & $5640-5659$ & & \\
\hline \multirow[t]{2}{*}{ sen } & ShET-2 upper & ATGTGCCTGCTATTATTTAT & $380-399$ & 799 & Vargas et al. (1999) \\
\hline & ShET-2 lower & CATAATAATAAGCGGTCAGC & $1158-1178$ & & \\
\hline \multirow[t]{2}{*}{$\operatorname{set} 1 A$} & ShET-1A upper & TCACGCTACCATCAAAGA & $460-477$ & 309 & Fasano et al. (1995) \\
\hline & ShET-1A lower & TATCCCCCTTTGGTGGTA & $751-768$ & & \\
\hline \multirow[t]{2}{*}{$\operatorname{set} 1 B$} & ShET-1B upper & GTGAACCTGCTGCCGATATC & $70-89$ & 147 & Fasano et al. (1995) \\
\hline & ShET-1B lower & ATTAGTGGATAAAAATGACG & $197-216$ & & \\
\hline \multirow[t]{2}{*}{$s t x_{1}$} & stx $x_{1}$ upper & ACCCTGTAACGAAGTTTGCG & - & 140 & Bonnet et al. (1998) \\
\hline & st $x_{1}$ lower & ATCTCATGCGACTACTTGAC & & & \\
\hline
\end{tabular}

raised against KIVI 162. This was confirmed by the ESYV reference laboratory in London, but the isolates did react with an antiserum against a provisionally recognized S. dysenteriae serotype, E112707-96 (unpublished data).

\section{Antibiotic susceptibility}

All isolates were resistant to trimethoprim-sulfamethoxazole, tetracycline and ampicillin and were susceptible to nalidixic acid, ciprofloxacin, ceftriaxone and mecillinam.

\section{Test for invasiveness}

Congo red dye was bound by all isolates and they caused keratoconjunctivitis in the guinea pig eye within $48 \mathrm{~h}$.

\section{Virulence pathogenicity}

All isolates were positive for $i a l, i p a H$ and sen genes and were negative for $s t x_{1}$ and set 1 genes. In contrast, the provisional strain E112707-96 was negative for ial and sen genes and only positive for $i p a H$.

\section{Plasmid DNA}

All isolates harboured the $140 \mathrm{MDa}$ invasive plasmid and two other plasmids of approximately 2.7 and 2.0 MDa in size. This plasmid pattern was different from that of other Shigella serotypes tested, including the provisional strain E112707-96, which lacked the $140 \mathrm{MDa}$ plasmid but contained another plasmid of approximately $65 \mathrm{MDa}$.

\section{PFGE}

All isolates were indistinguishable from each other by their $X b a I$ restriction pattern. This pattern differed markedly from that of other serotypes, including the provisional $S$. dysenteriae serotype E112707-96 (Fig. 1).

\section{DISCUSSION}

SLOs are consistently isolated from the hospitalized diarrhoeal population in Bangladesh. During the period 1999-2002, S. flexneri accounted for $60 \%$ of the total Shigella infections followed by $S$. boydii (17\%), S.

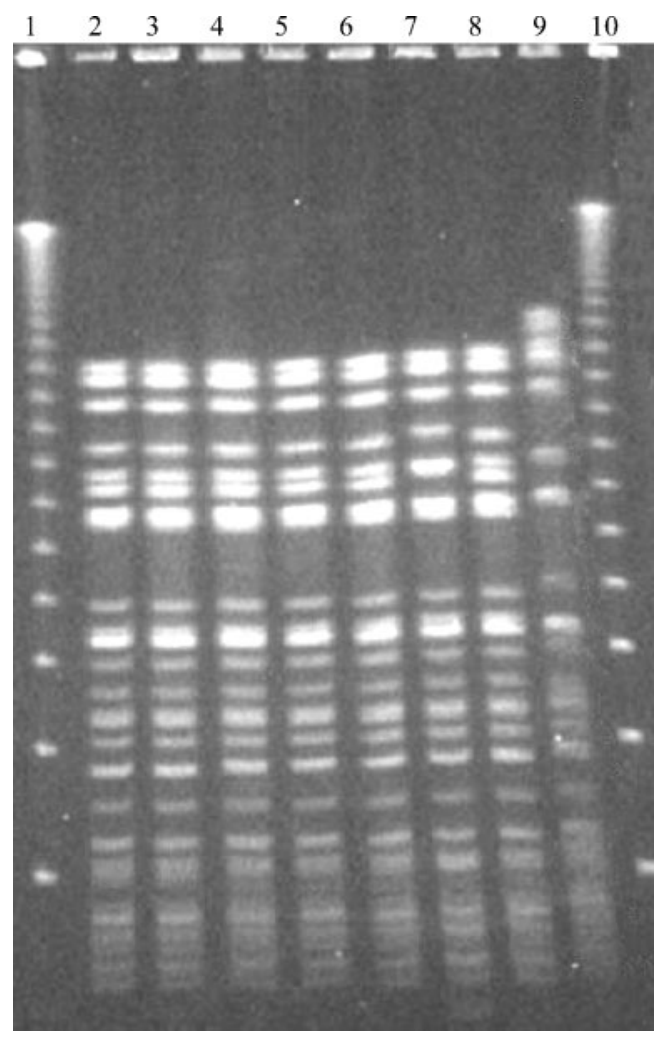

Fig. 1. PFGE patterns of $X b a l$-digested chromosomal DNA from seven SLOs and provisional S. dysenteriae serotype E112707-96. Lanes: 1 and 10, lambda molecular mass ladders; 2-8, SLO isolates; 9, provisional $S$. dysenteriae serotype E112707-96. 
Table 2. Characteristics of the SLOs studied

- , Negative; +, positive.

\begin{tabular}{|c|c|c|c|c|c|c|c|c|c|c|c|c|}
\hline \multirow[t]{2}{*}{ Strain no. } & \multirow[t]{2}{*}{ Biotyping ${ }^{\star}$} & \multirow[t]{2}{*}{$\begin{array}{c}\text { Antibiotic } \\
\text { susceptibility } \dagger\end{array}$} & \multicolumn{5}{|c|}{$\begin{array}{c}\text { Presence of } \\
\text { virulence/invasive genes }\end{array}$} & \multicolumn{3}{|c|}{ Test for invasiveness } & \multirow[t]{2}{*}{$\begin{array}{l}\text { Plasmid } \\
\text { typing } \neq\end{array}$} & \multirow[t]{2}{*}{$\begin{array}{l}\text { PFGE } \\
\text { typing }\end{array}$} \\
\hline & & & $s t x$ & set1 & set 2 & ial & ipaH & $140 \mathrm{MDa}$ & Sereny test & $\mathrm{CRB} \$$ & & \\
\hline KIVI 162 & B1 & $\mathrm{R} 1$ & - & - & + & + & + & + & + & + & P1 & A \\
\hline KIVI 165 & B1 & $\mathrm{R} 1$ & - & - & + & + & + & + & + & + & $\mathrm{P} 1$ & A \\
\hline KIVI 185 & B1 & $\mathrm{R} 1$ & - & - & + & + & + & + & + & + & $\mathrm{P} 1$ & A \\
\hline KIVI 217 & B1 & $\mathrm{R} 1$ & - & - & + & + & + & + & + & + & P1 & $\mathrm{A} 1$ \\
\hline KIVI 219 & B1 & $\mathrm{R} 1$ & - & - & + & + & + & + & + & + & P1 & A \\
\hline E112707-96 & B2 & $\mathrm{R} 2$ & - & - & - & - & + & - & - & - & P2 & B \\
\hline
\end{tabular}

${ }^{\star}$ B1, Glucose + , arabinose + , maltose + , arginine + ; B2, glucose + , arabinose + , maltose + , arginine + , mannose + .

$\dagger \mathrm{R} 1, \mathrm{Amp}^{\mathrm{r}} \mathrm{Sxt}^{\mathrm{r}} \mathrm{Tet}^{\mathrm{r}} \mathrm{Mel}^{\mathrm{s}} \mathrm{Nal}^{\mathrm{s}} \mathrm{Cip}^{\mathrm{s}} ; \mathrm{R} 2, \mathrm{Amp}^{\mathrm{r}} \mathrm{Sxt}^{\mathrm{s}} \mathrm{Tet}^{\mathrm{r}} \mathrm{Mel}^{\mathrm{s}} \mathrm{Nal}^{\mathrm{s}} \mathrm{Cip}^{\mathrm{s}}$.

$\ddagger \mathrm{P} 1,140,2.7,2.0 \mathrm{MDa}$; P2, 65, 3, $1.8 \mathrm{MDa}$.

$\$ \mathrm{CRB}$, Congo red binding ability.

dysenteriae (12\%) and S. sonnei (8\%) then SLOs (3\%) (Talukder et al., 2003). Serological classification is insufficient for the identification of novel Shigella species and a polyphasic approach utilizing biochemical, serological and molecular characterization is advocated (Ansaruzzaman et al., 2005). In this study, we characterized seven SLO isolates recovered over 3 years in hospitalized patients with diarrhoea (Table 2). They all had biochemical properties compatible with $S$. dysenteriae and had an antimicrobial resistance profile (ampicillin, tetracycline and trimethoprim-sulfamethoxazole) common among $S$. flexneri and S. dysenteriae isolates in Bangladesh (Talukder et al., 2002). Among the serotypes of Shigella, S. dysenteriae type 1 is generally the most resistant to antibiotics and appears to readily acquire resistance to newly introduced antibiotics for Shigella infection (Talukder et al., 2004). Indeed, all $S$. dysenteriae type 1 isolates in Bangladesh in 2004 and onwards are resistant to ciprofloxacin (Talukder et al., 2004). However, none of the seven SLO isolates was resistant to ciprofloxacin.

Although pathogenicity tests are not fundamental criteria for the classification of members of the Enterobacteriaceae, the findings of a positive Sereny test, the presence of a 140 MDa plasmid and the identification of ial and $i p a H$ genes provide strong evidence in support of a classification in the genus Shigella. Two novel toxins, Shigella enterotoxin 1 (ShET-1) encoded by chromosomal gene set 1 and Shigella enterotoxin 2 (ShET-2) encoded by sen (located in the 140 MDa plasmid), have been associated with the pathogenicity of many Shigella species (Nataro et al., 1995; Noriega et al., 1995). To date, $S$. dysenteriae 1 is the only serotype that has been reported to produce Shiga toxin 1 and some E. coli strains produce Shiga-like toxin 1 and 2. Strains belonging to the other serotypes of the Shigella group have not been shown to produce Shiga toxin.
Serotyping is considered to be essential for the confirmation of an organism as a member of the genus Shigella. An antiserum raised against one of the isolates in this study (KIVI 162) reacted only with the seven isolates but not with other Shigella or E. coli reference strains. Among E. coli pathotypes, enteroinvasive E. coli are the most similar in biochemical and virulence properties to Shigella, which can sometimes makes differentiation difficult. However, the SLO isolates did react with antiserum to an existing provisional $S$. dysenteriae serotype, designated E112707-96 (unpublished data), and this strain was strongly agglutinated by serum KIVI 162, supporting their antigenic identity.

A common genetic lineage for the SLO isolates was indicated by their similarity in plasmid and chromosomal DNA profiles. In the latter, one isolate exhibited the loss of a major band and the appearance of two minor bands in comparison with the others, but this difference was insufficient to distinguish between the isolates by the criteria of Tenover et al. (1995).

In summary, the SLO isolates characterized in this report exhibited traits characteristic of the genus Shigella in biochemical, serological and molecular properties. No serological cross-reactivity was observed with other Shigella and E. coli strains, except for an unpublished provisional S. dysenteriae serotype, E112707-96, isolated and identified by the E. coli reference laboratory in 1996. These isolates possess an antigenic epitope that sets this group apart from all other recognized strains of Shigella and we propose that they represent a novel emerging serovar of $S$. dysenteriae, type strain KIVI 162.

\section{ACKNOWLEDGEMENTS}

This study was shared by the United States Agency for International Development (USAID) under Cooperative Agreement No. HRN-A00-96-90005-00 and the ICDDR,B: Centre for Health and Population 
Research, which is supported by countries and agencies who share its concern for the health problems of developing countries. Current donors providing unrestricted support include: Australian International Development Agency (AusAID), Australia; Canadian International Development Agency (CIDA), Canada; Centre endowment fund; Department for International Development (DFID), UK; Government of Bangladesh (GoB); Government of Sri Lanka; Kingdom of Saudi Arabia (KSA); Government of the Netherlands; Swedish International Development Cooperative Agency (Sida), Sweden; and Swiss Development Cooperation (SDC), Switzerland. ICDDR, B acknowledges with gratitude the commitment of USAID to the Centre's research efforts.

\section{REFERENCES}

Ansaruzzaman, M., Sultana, M., Talukder, K. A., Alam, K., Matsushita, S., Safa, A., Khajanchi, B. K., Dutta, D. K., Islam, Z. \& other authors (2005). Isolation and characterization of provisional serovar Shigella boydii E16553 from diarrhoeal patients in Bangladesh. J Med Microbiol 54, 477-480.

Bonnet, R., Souweine, B., Gauthier, G., Rich, C., Livrelli, V., Sirot, J., Joly, B. \& Forestier, C. (1998). Non-O157 : H7 Stx2-producing Escherichia coli strains associated with sporadic cases of hemolyticuremic syndrome in adults. J Clin Microbiol 36, 1777-1780.

Bopp, C. A., Brenner, F. W., Fields, P. L., Wells, J. G. \& Strockbine, N. A. (2003). Escherichia, Shigella, and Salmonella. In Manual of Clinical Microbiology, 8th edn, pp. 654-671. Edited by P. R. Murray and others. Washington, DC: American Society for Microbiology.

Clinical and Laboratory Standards Institute (2004). Performance Standards for Antimicrobial Susceptibility Testing, approved standard, 14th edn, document M100-S14.Villanova, PA: Clinical and Laboratory Standards Institute.

Coimbra, R. S., Lenormand, P., Grimont, F., Bouvet, P., Matsushita, S. \& Grimont, P. A. D. (2001). Molecular and phenotypic characterization of potentially new Shigella dysenteriae serotypes. $J$ Clin Microbiol 39, 618-621.

DuPont, H. L., Levine, M. M., Hornick, R. B. \& Formal, S. B. (1989). Inoculum size in shigellosis and implications for expected mode of transmission. J Infect Dis 159, 1126-1128.

Enterobacteriaceae Subcommittee of the Nomenclature Committee of the International Association of Microbiological Societies (1958). Supplement to the third report on the Shigella group. Int Bull Bacteriol Nomencl Taxon 8, 93-95.

Ewing, W. H. (1986). The genus Shigella. In Identification of Enterobacteriaceae, 4th edn, pp. 135-172. Edited by W. H. Ewing. New York: Elsevier Science Publishing.

Ewing, W. H. \& Lindberg, A. A. (1984). Serology of Shigella. Methods Microbiol 14, 113-142.

Ewing, W. H., Reavis, R. W. \& Davis, B. R. (1958). Provisional Shigella serotypes. Can J Microbiol 4, 89-107.

Fasano, A., Noriega, F. R., Maneval, D. R., Jr, Chanasongcram, S., Russell, R., Guandalini, S. \& Levine, M. M. (1995). Shigella enterotoxin 1: an enterotoxin of Shigella flexneri 2a active in rabbit small intestine in vivo and in vitro. J Clin Invest 95, 2853-2861.

Gross, R. J., Thomas, L. V. \& Rowe, B. (1980). New provisional serovar (E10163) of Shigella boydii. J Clin Microbiol 12, 167-169.

Gross, R. J., Thomas, L. V., Day, N. P., Cheasty, T. \& Rowe, B. (1982). New provisional serovar of Shigella boydii. J Clin Microbiol 16, $1000-1002$.

Kado, C. I. \& Liu, S. T. (1981). Rapid procedure for detection and isolation of large and small plasmid. J Bacteriol 145, 1365-1373.
Kotloff, K. L., Winickoff, J. P., Ivanoff, B., Clemens, J. D., Swerdlow, D. L., Sansonetti, P. J., Adak, G. K. \& Levine, M. M. (1999). Global burden of Shigella infections: implications for vaccine development and implementation of control strategies. Bull World Health Organ 77, 651-666.

Melito, P. L., Woodward, D. L., Munro, J., Walsh, J., Foster, R., Tilley, P., Paccagnella, A., Isaac-Renton, J., Ismail, J. \& Ng, L. K. (2005). A novel Shigella dysenteriae serovar isolated in Canada. J Clin Microbiol 43, 740-744.

Nataro, J. P., Seriwatana, J. A., Fasano, A., Maneval, D. R., Guers, L. D., Noriega, F., Dubovsky, F., Levine, M. M. \& Morris, J. G., Jr (1995). Identification and cloning of a novel plasmid-encoded enterotoxin of enteroinvasive Escherichia coli and Shigella strains. Infect Immun 63, 4721-4728.

Noriega, F. R., Liao, F. M., Formal, S. B., Fassano, A. \& Levine, M. M. (1995). Prevalence of Shigella enterotoxin 1 among Shigella clinical isolates of diverse serotypes. J Infect Dis 172, 1408-1410.

Sasakawa, C., Kamata, K., Sakai, T., Murayama, S. Y., Makino, S. \& Yoshikawa, M. (1986). Molecular alteration of the 140-megadalton plasmid associated with loss of virulence and Congo red binding activity in Shigella flexneri. Infect Immun 51, 470-475.

Sereny, B. (1957). Experimental keratoconjunctivitis Shigellosa. Acta Microbiol Acad Sci Hung 2, 367-376.

Talukder, K. A., Islam, M. A., Dutta, D. K., Hassan, F., Safa, A., Nair, G. B. \& Sack, D. A. (2002). Phenotypic and genotypic characterization of serologically atypical strains of Shigella flexneri type 4 isolated in Dhaka, Bangladesh. J Clin Microbiol 40, 2490-2497.

Talukder, K. A., Islam, M. A., Khajanchi, B. K., Dutta, D. K., Islam, Z., Safa, A., Alam, K., Hossain, A., Nair, G. B. \& Sack, D. A. (2003). Temporal shifts in the dominance of serotypes of Shigella dysenteriae from 1999 to 2002 in Dhaka, Bangladesh. J Clin Microbiol 41, 5053-5058.

Talukder, K. A., Khajanchi, B. K., Islam, M. A., Dutta, D. K., Islam, Z., Safa, A., Khan, G. Y., Alam, K., Hossain, M. A. \& other authors (2004). Genetic relatedness of ciprofloxacin-resistant Shigella dysenteriae type 1 strains isolated in south Asia. J Antimicrob Chemother 54, 730-734.

Tenover, F. C., Arbeit, R. D., Goering, R. V., Mickelsen, P. A., Murray, B. E., Persing, D. H. \& Swaminathan, B. (1995). Interpreting chromosomal DNA restriction patterns produced by pulsed-field gel electrophoresis: criteria for bacterial strain typing. J Clin Microbiol 33, 2233-2239.

Vargas, M., Gascon, J., Jimenez De Anta, M. T. \& Vila, J. (1999). Prevalence of Shigella enterotoxin 1 and 2 among Shigella strains isolated from patients with traveler's diarrhea. J Clin Microbiol 37, 3608-3611.

Wathen-Grady, H. G., Davis, B. R. \& Morris, G. K. (1985). Addition of three new serotypes of Shigella boydii to the Shigella schema. J Clin Microbiol 21, 129-132.

Weissman, J. B., Gangorosa, E. J., Schemerler, A., Marier, R. L. \& Lewis, J. N. (1975). Shigellosis in day-care centres. Lancet 1, 88-90.

World Health Organization (1987). Programme for control of diarrhoeal disease. In Manual for Laboratory Investigation of Acute Enteric Infections, pp. 9-20. CDD/93.3, Rev. 1. Geneva: World Health Organization.

Woodward, D. L., Clark, C. G., Caldeira, R. A., Ahmed, R., Soule, G., Bryden, L., Tabor, H., Melito, P., Foster, R. \& other authors (2005). Identification and characterization of Shigella boydii 20 serovar nov., a new and emerging Shigella serotype. J Med Microbiol 54, $741-748$ 